\title{
Criatividade em Debate: Algumas Contribuições da Análise do Comportamento
}

\author{
Silvia Cristiane Murari ${ }^{1}$ \\ Departamento de Psicologia Geral e Análise do Comportamento da Universidade Estadual \\ de Londrina, Londrina, Brasil \\ Marcelo Henrique Oliveira Henklain \\ Departamento de Psicologia, Universidade Federal de São Carlos, São Carlos, Brasil
}

\begin{abstract}
Resumo
As publicações sobre o tema criatividade nas perspectivas da Teoria Psicanalítica, da Gestalt e do humanismo predominaram o cenário da psicologia no Brasil. Entretanto, nos últimos 20 anos, surgiram novas perspectivas teóricas que tem contribuído para o desenvolvimento do conhecimento a respeito desse fenômeno. Considerando a produção de conhecimento da Análise do Comportamento nas últimas três décadas, chama atenção que esta não apareça como uma das abordagens que têm contribuído para o avanço na definição e estudo da criatividade. As razões para este fato podem envolver muitos fatores desde pouca divulgação da produção até preconceitos e mal entendidos com a filosofia que sustenta a Análise do Comportamento e com os próprios conceitos dessa área. Os objetivos deste texto são apresentar alguns princípios importantes da Análise do Comportamento para a compreensão do comportamento criativo, apresentar duas contribuições comportamentais para a análise dessa classe de comportamentos, a saber, as noções de combinações de repertórios e de variabilidade, e apresentar algumas decorrências dessas análises do comportamento criativo para a educação.
\end{abstract}

Palavras-chave: Análise do comportamento, comportamento criativo, educação de comportamento criativo.

\section{Creativity in Focus: Some Contributions of the Analysis of Behavior}

\begin{abstract}
Most of the publications on creativity were oriented by psychoanalytic, gestalts, or humanistic perspectives, in the Brazilian scenery of psychology. In the last years, new theoretical perspectives, as Analysis of Behavior, appeared. This approach has contributed to the development of creativity. However, considering the production of Analysis of Behavior on the last three decades, it is a surprise that it does not appear as one of the major approaches that contributed to the definition and to the study of creativity. Some reasons may be pointed out to give an account for that absence. First, little attention has been paid to the Analysis of Behavior's production. Second, there are prejudices and misunderstandings related to the philosophy that underlies the Analysis of Behavior. The objectives of this paper are to show how principles of behavior analysis stand as tools for understanding the creative behavior. This paper also intends to make two contributions to the behavioral analysis of creative behavior. First, to present the
\end{abstract}

Endereço para correspondência: Centro de Ciências Biológicas, Departamento de Psicologia Geral e Análise do Comportamento, Universidade Estadual de Londrina, Campus Universitário, Londrina, PR, Brasil 86057 970. Caixa-postal: 10011. E-mail: murari@uel.bre marcelo_henklain@hotmail.com 
notions of interconnection of repertoires and variability, and present some implications of these analyzes of creative behavior in education.

Keywords: Behavior analysis, creative behavior, education of creative behavior.

\section{Creatividad en Debate: Algunas Contribuciones del Análisis del Comportamiento}

\section{Resumen}

Las publicaciones sobre el tema creatividad en las perspectivas de la Teoría Psicoanalítica, de Gestalt y del humanismo predominaron en el escenario de la psicología en Brasil. Sin embargo, en los últimos 20 años, surgieron nuevas perspectivas teóricas que han contribuido para el desarrollo del conocimiento sobre este fenómeno. Considerando la producción del producción de conocimiento de Análisis del Comportamiento en las últimas tres décadas sobre ese tema, llama la atención que ésta no aparezca como uno de los abordajes que han contribuido para el avance en la definición y estudio de la creatividad. Las razones para este hecho pueden envolver muchos factores desde poca divulgación de la producción hasta preconceptos y mal entendidos con la filosofía que sostiene el Análisis del Comportamiento y los mismos conceptos que la zona. El objetivo de este texto es aclarar algunos principios importantes del Análisis del Comportamiento para la comprensión del comportamiento creativo, presentar dos contribuciones comportamentales para el análisis de esta clase de comportamientos, a saber, las nociones de interconexión de repertorios y de variabilidad, y presentar algunas consecuencias de esos análisis del comportamiento creativo para la educación.

Palabras clave: Análisis del comportamiento, comportamiento creativo, educación de la conduta creativa.

A Psicologia é apenas parte do empreendimento científico, mas uma parte fundamental dado o seu papel de disciplina científica responsável por investigar e apresentar parâmetros de entendimento do comportamento (Skinner, 1981). Junto a ela outros campos do saber científico como a etologia, a fisiologia, a antropologia e a moderna ciência do cérebro, além de outras áreas de conhecimento, completam esse empreendimento. Mas, no que diz respeito às relações entre as ações de uma pessoa e o ambiente em que ela os realiza (público e privado, histórico e imediato, social e não-social) ao longo de uma história de vida particular, cabe a Psicologia tomar a frente dos estudos sobre um dos aspectos intrigantes do comportamento humano, a criatividade.

De acordo com o trabalho de Zanella e Titon (2005) de modo geral são os fundamentos da Teoria Psicanalítica, da Gestalt e dos representantes da Psicologia Humanista que têm sido tomados como referência para as discussões do tema criatividade. Alencar e Fleith (2003) examinaram a literatura sobre Psicologia da Criatividade no Brasil e constataram que, nos últimos 20 anos, novas contribuições surgiram, entretanto, elas ainda não estão sendo contempladas por autores brasileiros. Segundo a análise dessas autoras, nas novas concepções ou conceitos a respeito de criatividade o foco deixa de ser o delineamento do perfil do indivíduo criativo acompanhado de técnicas e meios de expressão da criatividade e passa a ser a investigação das variáveis do contexto sócio-histórico-cultural envolvidas no comportamento criativo.

O resultado dos estudos de Alencar e Fleith (2003) chama a atenção pelo fato de que em nenhum momento as contribuições da Análise do Comportamento foram consideradas para esse novo tipo de análise da criatividade, embora a Análise do Comportamento tenha como foco o estudo da interação da pessoa (organismo bioló- 
gico com uma história particular) com seu ambiente (variáveis físicas e sociais ${ }^{2}$ ), por meio de sua atividade nesse meio. A ausência de citação dessa contribuição específica sugere que, mesmo por parte dos pesquisadores que estudam criatividade, ela deve ser pouco conhecida ou então mal compreendida.

Dessa forma, antes de apresentar alguns conceitos propostos pela Análise do Comportamento para a compreensão do comportamento criativo, as contribuições comportamentais para a análise dessa classe de comportamento, e ainda, as decorrências desta para o contexto educacional, parece relevante uma breve exposição do contexto do conhecimento no qual a Análise do Comportamento surge, de alguns dos seus principais fundamentos filosóficos e como eles impactam na forma do analista do comportamento fazer ciência e explicar o comportamento humano.

Feito isso, espera-se que esta breve revisão de literatura contribua com pesquisadores interessados no tratamento analítico-comportamental da criatividade.

\section{Análise do Comportamento: Alguns Fundamentos Filosóficos e Científicos}

A psicologia do final do século 19 e início dos 20 era definida como uma ciência que buscava conhecer a mente humana. Neste contexto o objeto de estudo da psicologia era a consciência humana e a introspecção o método para acessá-la (Tourinho, 1987). Segundo Schneider e Morris (1987), o rompimento com essa tradição científica da psicologia tem início com o artigo de Watson de 1913 intitulado Psychology as the Behaviorist Views It. As posições defendidas por Watson, sucintamente, eram o abandono da consciência como objeto de estudo em defesa do comportamento dos organismos e o abandono da introspecção pela experimentação como método de investigação científica. Assim como Watson muitos outros estudiosos, da época, ansiavam

2 Incluem-se em social as pessoas e as regras de uma cultura. por uma guinada nas questões teórico-metodológicas da psicologia em direção à defesa da objetividade (Carrara, 2005). Estabeleciam-se assim os contornos de uma nova perspectiva científica para a psicologia, na qual o conceito de ciência e a natureza dos fenômenos psicológicos foram redefinidos. Watson chamou esta proposta de Behaviorismo (Carvalho-Neto, 2002). Apesar do caráter inovador e desafiador da proposta behaviorista defendida por Watson, elegia-se para estudo apenas comportamentos observáveis e tangíveis e, prematuramente, excluía-se do novo modelo de ciência parte das ações humanas, aquelas que não podiam ser vistas ou tocadas (que mais tarde seriam conhecidas como eventos privados).

Sob influência desta nova proposta de ciência ganha força o operacionismo baseado na obra de Percy Bridgman, de 1928, intitulada The Logic of Modern Physics. Para este autor, de um modo geral, os conceitos não deveriam ser definidos em termos de suas propriedades, e sim a partir de um conjunto de operações relativas as circunstâncias nas quais são empregados. Isto garantiria que os conceitos científicos pudessem ser revistos à medida que as pesquisas avançassem. Paralelamente, surge um grupo de operacionistas sobre forte influência positivista que valoriza demasiadamente a objetividade proposta por Bridgman, como resultado tem-se uma ciência dos fenômenos publicamente observáveis, fundamentada num critério de verdade por consenso público. Skinner contrapõem-se as propostas apresentadas por este grupo e denomina-o behavioristas metodológicos por privilegiarem o método mais do que o próprio objeto de estudo (Micheletto, 1997; Schneider \& Morris, 1987; Skinner, 1989/1991; Tourinho, 1987).

As contraposições de Skinner foram apresentadas em um importante artigo, escrito por ele em 1945, intitulado The Operational Analysis of Psychological Terms. Neste Skinner defende a natureza não distintiva entre eventos privados e públicos, no sentido em que eventos privados são tão físicos (enquanto naturais) quanto os eventos que ocorrem publicamente eliminando, assim, uma perspectiva dualista do comportamento; critica o critério de verdade por 
concordância pública em defesa de um critério mais pragmático; e por fim, apresenta o esboço de uma teoria funcional para a análise das respostas verbais que permite a análise de eventos privados. Verifica-se nestas propostas a grande revolução na forma de estudar cientificamente os chamados fenômenos psicológicos (Abib, 1994). Pode-se dizer que a partir deste artigo as bases do Behaviorismo Radical que sustentarão a Análise Experimental do Comportamento (método de investigação científica do comportamento) e a Análise Aplicada do Comportamento (criação e administração de recursos de intervenção social) começaram a se consolidar (Tourinho, 1999).

Nas palavras de Todorov (2007):

Nessa caracterização da Psicologia, o homem é visto como parte da natureza. Nem pairando acima do reino animal, como viram pensadores pré-darwinianos, nem mero robô, apenas vítima das pressões do ambiente, na interpretação errônea feita por alguns autores de um comportamentalismo inexistente. Os homens agem sobre o mundo, modificam-no e, por sua vez, são modificados pelas consequências de sua ação. Alguns processos que o organismo humano compartilha com outras espécies alteram o comportamento para que ele obtenha um intercâmbio mais útil e mais seguro em determinado meio ambiente. Uma vez, estabelecido um comportamento apropriado, suas consequências agem por meio de processo semelhante para permanecerem ativas. Se, por acaso, o meio se modifica, formas antigas de comportamento desaparecem enquanto novas consequências produzem novas formas (Todorov, 2007, p. 58).

Segundo Skinner (1953/1998) "a ciência é antes de tudo um conjunto de atitudes" (p. 12). Com esta frase Skinner coloca em destaque o comportamento do cientista. Assim, a ciência não pode ser compreendida, como já foi um dia, a partir do seu local de realização (laboratórios, por ex.), de seus instrumentos (telescópios, microscópios), nem da exatidão dos cálculos (medidas estatísticas), tampouco como a via pela qual se produz "a verdade". Ciência já foi definida como: conhecimento filosófico racional, absoluto e sistemático a respeito da essência do real, culminância de todos os saberes particulares e específicos. Do ponto de vista skinneriano, contudo, deve-se olhar para a Ciência como produto dos comportamentos dos cientistas sob influência das contingências que controlam seus comportamentos de produção de conhecimento, nessa modalidade ou forma de conhecer.

Para Skinner (1953/1998) o produto da ciência deve capacitar-nos a manejar um fenômeno ou processo de modo mais eficiente.

Quando já tivermos descoberto as leis que governam uma parte do mundo ao nosso redor, e quando tivermos organizado estas leis em um sistema, estaremos então preparados para lidar eficientemente com esta parte do mundo (Skinner, 1953/1998, p. 26).

Pode-se dizer assim que, do ponto de vista skinneriano, uma ciência está comprometida com a previsão e o controle (no sentido de controle das variáveis que interferem com o fenômeno "comportamento" o que não significa apenas "controle social" como é frequente ocorrer confusão). Isto parece não ser problema quando inserido no contexto das ciências físicas e biológicas, mas parece inconcebível dentro do contexto das ciências humanas. Provavelmente, a recusa ou resistência a uma ciência do comportamento humano, origine-se do credo de que ela acabaria com a liberdade e a criatividade humana. Propor que nossas ações são determinadas e, portanto, previsíveis pode constituir a ideia de que o homem é uma máquina; de que o comportamento humano é simples e não complexo; linear e não mutável.

Ao contrário do que se imagina, previsão e controle podem ser responsáveis por maiores graus de liberdade. Quando se diz que é possível prever um comportamento, não significa propriamente dizer qual será o futuro da pessoa, mas da probabilidade de haver um tipo de interação da atividade de um organismo com aspectos de seu ambiente, um tipo de comportamento. Quando um cientista prevê que a Terra poderá se tornar atmosfericamente inabitável em alguns poucos anos, como resultado da combinação de diversas variáveis (poluição, desmatamento, produção de lixo etc.), tal previsão probabilística 
é ou pode ser utilizada para alterar condições que estão produzindo efeitos danosos a Terra e com isto alterar a probabilidade de que os problemas possam se agravar. Quando alguém prevê que uma pessoa não irá fazer faculdade no próximo ano como resultado da combinação das diversas variáveis (tipo de material usado para estudo, horas de leitura, local de estudo etc.), utiliza esta descrição para alterar essas condições (por exemplo, aumentar o tempo de leitura, mudar o material didático, escolher outro local, talvez mais iluminado, sem distrações etc.). Ao alterar as condições que determinam a ocorrência dessas variáveis altera-se (aumenta-se) a probabilidade de uma pessoa ter sucesso no estudo. Isso significa que, quanto mais soubermos quais e como certas variáveis afetam o comportamento, maior será a liberdade de mudar caminhos e alterar o futuro. Em termos gerais, o objetivo final de uma ciência do comportamento é a produção de conhecimentos que possam trazer autoconhecimento ao ser humano, torná-lo consciente do que faz e oferecer estratégias comportamentais que ampliem o processo de decisão, resolução de seus problemas e do grupo do qual faz parte (Skinner, 1953/1998, 1974/1999), além de, é claro, criar a possibilidade de que cada um possa identificar controles que são exercidos em relação a seu próprio comportamento ou a comportamento alheio.

Uma ciência do comportamento, nos moldes skinnerianos, só é viável concebendo o comportamento humano como um evento natural que dispensa qualquer construto hipotético interior como agente causal (iniciador) do comportamento. Para uma cultura ocidental que sempre colocou o homem em um patamar de superioridade evolutiva, a posição skinneriana é tida, muitas vezes, como uma blasfêmia, tal como a postura de Darwin a respeito da evolução das espécies.

Considerando que ciência é um conjunto de comportamentos de cientistas, toda a escolha de um procedimento de investigação e a análise dos dados produzidos tem por base um referencial filosófico e determinante de natureza conceitual, como controles de estímulos em relação a determinadas classes de comportamentos. Segundo
Micheletto (1997), muitas das críticas que o pensamento de Skinner recebeu apontam-no como mecanicista, redutor do homem, representante da psicologia estímulo-resposta (input-output). Contudo, seus críticos parecem desconsiderar o fato de que, desde seus primeiros trabalhos (Skinner, 1931, 1935, 1938) há um contínuo afastamento do mecanicismo e da "psicologia estímulo-resposta", como apontado anteriormente neste texto. Tais críticos desconsideram ainda que, mesmo seus primeiros trabalhos, buscam enfatizar um tipo de ação do organismo que produz o meio que o determina. Tal contribuição é afirmada com o conceito de comportamento operante e que está longe de considerar o homem como passivo em seu processo evolutivo (Skinner, 1957/1978).

O comportamento [operante] não pode ser entendido isolado do contexto em que ocorre. Não há sentido em uma descrição de comportamento sem referência ao ambiente, como não há sentido, para a Psicologia, em uma descrição do ambiente apenas. A descrição "Maria correu" é inútil para a análise do comportamento; sem antecedentes e consequentes do evento descrito, nada se pode concluir do episódio. Os conceitos de comportamento e ambiente e de resposta e estímulo são interdependentes. Um não pode ser definido sem referência ao outro (Todorov, 2007, p. 59).

A posição de Skinner é influenciada, também, pelas ciências biológicas especificamente pela teoria da evolução por seleção natural de Darwin (1809-1882).

Vimos que em certo aspecto o reforço operante se assemelha à seleção natural da teoria da evolução. Assim como as características genéticas que surgem como mutações são selecionadas ou rejeitadas por suas conseqüências, também novas formas de comportamento são selecionadas ou rejeitadas pelo reforço (Skinner, 1953/1998, p. 402).

Gradualmente, vê-se na obra de Skinner, que os princípios da seleção natural vão delineando seu modelo explicativo chamado de Seleção pelas Conseqüências. Em linhas gerais o modelo proposto oficialmente em 1981, declara 
que o comportamento humano - que é o interesse fundamental de Skinner ${ }^{3}$ - é produto de três processos de variação e seleção a partir de: (a) contingências de sobrevivência - cujo efeito é a evolução da espécie e conseqüentemente das características e comportamentos específicos dela; (b) contingências de reforço - cujo efeito é o repertório comportamental do indivíduo caracterizado pela diversidade de comportamentos e; (c) contingências culturais - cujo efeito é sobre práticas de grupo (Skinner, 1981). Os três processos de variação e seleção ocorrem concomitantemente e possibilitam que o comportamento seja entendido como multideterminado. A multideterminação não significa acrescentar mais variáveis à análise, mas sim destacar os efeitos que diferentes interações entre organismo e ambiente podem produzir. Tem-se, neste modelo, uma rede de interações e não relações linearmente encadeadas como no mecanicismo (Chiesa, 2006). Compreender o comportamento humano exige considerar na análise, no mínimo, o indivíduo (como resultante de variáveis filogenéticas e ontogenéticas) inserido em um contexto social (comportamentos de outras pessoas) e em um ambiente físico atual.

Deste ponto de vista, as concepções skinnerianas excluem claramente as noções de mente, de propósito e intenções como agentes iniciadores do comportamento. São as conseqüências presentes que determinam a probabilidade de ocorrência do comportamento em uma situação futura semelhante. Isso não significa dizer que as conseqüências são acumuladas em uma mente ou memorizadas pelo homem para que sejam recuperadas e orientem uma ação planejada que possa gerar maior adaptação. Significa que os efeitos das interações do indivíduo com seu

3 A pesquisa com animais não tem o objetivo de comparar comportamentos de não humanos e humanos, mas estudar "como eles atuam (funcionam) nas suas relações com o ambiente . . . Skinner pretende justificar o empreendimento de pesquisa laboratorial prévio com animais enquanto forma de aprimoramento tecnológico preliminar à pesquisa com humanos" (Carrara, 2005, p. 174). Além disso, "processos importantes do comportamento mostram generalidades filogenéticas" (Carrara, 2005, p. 175). ambiente físico e social modificam o organismo (Skinner, 1981), tornando-o um produto singular, pois subjacentes aos processos comportamentais encontram-se alterações funcionais e morfológicas que ocorrem no sistema nervoso e que caracterizam a plasticidade neural, definem a modificação do organismo, indo além das alterações nas características de sua atividade. Nas duas últimas décadas, a noção de organismo modificado tem sido fortalecida pelos achados das pesquisas em neurociências (Cerutti, Ferrari, Toyoda, \& Faleiros, 2001). Apesar disto as interações entre atividade (apresentação de classes de respostas no ambiente) e o funcionamento (bioquímico, neurológico, fisiológico etc.) do organismo ainda são pouco conhecidas e utilizadas nos trabalhos dos psicólogos de forma clara e precisa.

Há, ainda, dificuldades para conceber ou entender o ser humano e seu comportamento em termos de uma unidade integrada e probabilisticamente determinada. Isso ocorre, provavelmente, porque não se tem acesso à história pessoal e a história genética da espécie, o que torna difícil conceber como comportamentos complexos puderam surgir, considerando, ainda, que a teoria da evolução até a primeira década do século XXI, permanece polêmica. Como salientam Cupertino e Sampaio (2004) as brechas, de conhecimento ou de entendimento pessoal, criam oportunidades ou condições para explicações que encontram em construtos hipotéticos internos as causas para o comportamento humano complexo, como é o caso da criatividade: "campo fértil para especulações teóricas que procuram dar conta do terrível empreendimento que é defini-la" (p. 2).

\section{A Criatividade sob a Perspectiva da Análise do Comportamento}

Tendo como referencial os conceitos apresentados no que foi exposto até o momento, a primeira consideração a ser feita é que a Análise do Comportamento não estuda a criatividade e sim o comportamento criativo:

Esse cuidado, também tomado na referência a outros termos da linguagem não-científica ou adotados por algumas abordagens psico- 
lógicas, está relacionado à evitação de transformar uma propriedade do comportamento em um evento interno hipoteticamente deduzido (a criatividade), ao qual se atribui uma função causal do comportamento caracterizado como criativo. Privilegiando uma abordagem externalista do fenômeno, a análise do comportamento considera que a investigação do comportamento criativo demanda uma análise da interação entre o indivíduo e seu ambiente (Barbosa, 2003, p. 186).

Até o momento não há nenhum dado empírico que demonstre que o comportamento criativo, apesar de parecer aleatório e espontâneo, tenha uma natureza diferenciada de outros comportamentos. Ou seja, o comportamento criativo pode ser tão organizado e sujeito às mesmas leis como qualquer outro comportamento (Epstein, 2008; Hunziker, 2006). Sendo assim, também pode ser estudado cientificamente por meio da identificação das condições que alteram a probabilidade de sua ocorrência.

Segundo Hunziker (2006) encontra-se na literatura o consenso de que estudar comportamento criativo envolve como requisito o comportamento novo, ou seja, diferente de um comportamento que ocorreu anteriormente. Entretanto,

... a característica de ser novo/original/criativo não é propriedade do comportamento, mas sim é uma propriedade fornecida pelos referentes aos quais ele está sendo comparado, dentro de um universo particular. $\mathrm{Ou}$ seja, a caracterização do comportamento como criativo é mutante e relativa, o que torna sua análise bastante complexa (Hunziker, 2006, p. 157).

Considerando essa ressalva de que a classificação do comportamento como novo e criativo depende de parâmetros sociais, pode-se interpretar novidade ou diferença como variação de um comportamento. Pesquisas sobre variabilidade comportamental têm contribuído para o estudo da criatividade de um ponto de vista comportamental (Barba, 1997; Cruvinel, 2002; Duarte, 2004; Godoi, 2009; Hunziker, Camaroni, Silva, \& Barba, 1998; Hunziker \& Moreno, 2000;
Machado, 1993, 1997; Medeiros, 2002; Murari, 2004; Page \& Neuringer, 1985). Todos esses estudos demonstram que a variação pode ser produzida e, portanto, aprendida, o que sustenta a alegação de que é possível arranjar contextos nos quais os comportamentos criativos serão mais prováveis.

O modelo de variabilidade enfatiza que toda resposta de uma classe, como parte ou instância de um comportamento, sofre variações constantes nas suas diversas propriedades (topografia, força, magnitude e direção), há também variações em diferentes aspectos do meio em que tais respostas e suas variações ocorrem, de modo que, sempre existe algum tipo de variação comportamental ocorrendo, sendo o comportamento criativo aquela variação selecionada por seus efeitos (isto é, efeitos selecionadores e fortalecedores da interação entre propriedades das respostas de uma classe e propriedades dos estímulos componentes do meio no qual tais respostas são apresentadas). A conseqüência com função reforçadora pode ocorrer, por exemplo, quando alguma resposta de uma classe produz algum resultado útil (atende a um objetivo ou necessidade do organismo), quando traz alguma contribuição a um valor estético adotado por uma cultura (o que é habitualmente valorizado por um grupo social e punido quando alguém não valoriza), ou quando soluciona algum problema relacionado a uma condição aversiva do organismo (Hunziker, 2006).

Variações das respostas, e das interações com o ambiente, que produzem consequências com função reforçadora que antes não eram produzidas ou que produzem conseqüências reforçadoras com menor custo de resposta ou que produzem conseqüências com função reforçadora generalizada, tendem a ser selecionadas.

Além da variação comportamental como recurso de interpretação do comportamento criativo, segundo Barbosa (2003), na obra de Skinner encontram-se referências ao estudo do comportamento criativo como comportamento de resolução de problemas. Numa perspectiva comportamental, resolver problemas pode significar manipular o ambiente de modo a tornar mais provável a emissão da resposta que soluciona o 
problema ou ocorrência de combinações de repertórios previamente aprendidos diante de uma situação nova. Na primeira perspectiva, a pessoa tem diante de si uma situação-problema cuja solução depende de uma resposta que ela não consegue identificar qual seja. É possível que a resposta-solução não tenha sido aprendida ou as variáveis do contexto não estabeleçam condição para a sua ocorrência ou favoreçam respostas concorrentes (Donahoe \& Palmer, 1994). Portanto, o arranjo contextual não assume a função de estímulo discriminativo para a apresentação da resposta de uma classe, capaz de produzir a solução do problema: "o indivíduo não é capaz de identificar qual a resposta que produz um determinado reforçador; portanto, identifica o reforço, mas não a resposta" (Nico, 2001, p. 69) que poderá produzi-lo. Por exemplo, a pessoa:

(1) identifica o reforço (apresentar corretamente o conhecido para o amigo); (2) a resposta que produz o reforço faz parte de seu repertório comportamental (já disse alguma vez aquele nome, "sabe" dizê-lo), mas por qualquer razão, (3) não dispõe prontamente da resposta que produz o reforço. (Nico, 2001, p. 69).

Para solucionar o problema, é necessária a alteração em algum aspecto do ambiente com o qual o organismo interage. Resolver problemas é "mais do que emitir a resposta que lhe constitui a solução; é uma questão de dar os passos necessários para tornar tal resposta mais provável, via de regra mudando o ambiente" (Skinner, 1974/1999, p. 98); "a solução de problemas pode ser definida como qualquer comportamento que, através da manipulação de variáveis, torne mais provável o aparecimento de uma solução" (Skinner, 1953/1998, p. 239). Assim, resolver problemas envolve suplementar ou manipular estímulos discriminativos até que uma resposta particular do repertório do organismo torne-se mais forte que as demais respostas que também estão sendo evocadas pelos estímulos presentes na situação-problema. Essas manipulações terminam quando a contingência original (o problema) é satisfeita, ou seja, quando a resposta-solução é reforçada (Donahoe \& Palmer, 1994; Nico, 2001). Essas respostas de manipulação do ambiente são denominadas de respos- tas pré-correntes (Skinner, 1953/1998). Alguns exemplos de comportamentos pré-correntes são: aperfeiçoar ou ampliar a estimulação disponível e arranjar ou rearranjar estímulos. Diante de um problema, a pessoa ao atuar altera o seu contexto, de modo que, num determinado momento, poderá produzir um novo arranjo contextual capaz de aumentar a probabilidade de ocorrência do comportamento ou comportamentos capazes de solucioná-lo.

No caso da interpretação do comportamento de resolver problemas como combinações de repertórios, que tem sido empregada para analisar o insight, pesquisadores procuram demonstrar que os comportamentos necessários para resolver o problema haviam sido aprendidos ao longo da história da pessoa apesar de nunca terem ocorrido juntos. Nesse caso, determinadas variáveis ambientais podem favorecer a combinação desses repertórios previamente aprendidos, gerando um padrão novo de resposta; é possível falar em uma nova resposta, desde que se esteja ciente de que cada uma das respostas que, por efeito do arranjo contextual ocorreram ao mesmo tempo, já faziam parte do repertório da pessoa no sentido de que haviam sido aprendidas em outro momento de sua vida (Delage, 2006; Delage \& Carvalho-Neto, 2006).

Segundo Delage (2006), os padrões de comportamentos denominados criatividade ou insight:

... poderiam ser explicados alternativamente como sendo uma interconexão espontânea de repertórios previamente aprendidos. Esta interconexão se daria quando múltiplos comportamentos se tornassem disponíveis durante um processo de extinção, em um processo conhecido como ressurgência . . . ou por uma combinação de múltiplos estímulos de controle . . . Estes comportamentos poderiam se combinar para produzir novas seqüências . . comportamentos que tenham novas funções ... ou comportamentos que tenham novas topografias ... (Delage, 2006, p. 27)

O comportamento que soluciona uma situação-problema, segundo esses referenciais pode então ser classificado como comportamento criativo. 
Relacionando esses conceitos àqueles inicialmente apresentados sobre os fundamentos filosóficos da Análise do Comportamento, deve ficar claro que a pessoa só é livre, criativa e capaz de solucionar problemas, no sentido de que ao comportar-se (ao manipular variáveis) pode produzir modificações ambientais de modo a tornar mais provável a ocorrência de outras classes de respostas do seu próprio repertório.

\section{Implicações da Perspectiva Comportamental de Criatividade para a Educação e o Aprendizado de Comportamento Criativo}

A concepção de Skinner a respeito de educação salienta que é preciso ensinar aos alunos comportamentos que serão vantajosos para eles e para os outros em algum momento no futuro (Nico, 2001). Essa visão privilegia, portanto, valores como a solidariedade em vez do individualismo e considera não apenas o ambiente imediato, mas também o futuro. $\mathrm{O}$ desafio nesse sentido é grande quando se constata que o ambiente está constantemente sob mudança. Como ensinar comportamento que será vantajoso para a pessoa e para os outros numa condição futura ainda desconhecida?

Skinner responde a essa pergunta sugerindo que os alunos aprendam na escola um repertório especial "por meio do qual os próprios alunos podem chegar a comporta-se de forma eficiente sob novas contingências e sem o auxílio dos membros da agência educacional" (Nico, 2001, p. 63). Esse repertório especial diz respeito aos comportamentos de autocontrole, de decidir e solucionar problemas. Examinar os dois primeiros comportamentos foge ao escopo deste trabalho, mas será discutida a importância para a educação do comportamento de solucionar problemas, analisando-o como um tipo de comportamento criativo.

Skinner confere grande importância ao comportamento criativo, pois desenvolvê-lo seria uma das condições para permitir a liberdade, dignidade e autonomia dos homens diante de contextos sob constante mudança. Segundo esse autor, o ensino precisa valorizar e desenvolver comportamentos criativos dos alunos, e, por conseguinte, precisa, ele mesmo, ser um ensino criativo. Autores de diferentes contribuições em Psicologia também têm destacado a necessidade de uma educação mais criativa (Alencar, 2007).

De acordo com Alencar (2007), existem, resumidamente, três razões para essa valorização dos comportamentos criativos, a saber: (a) criar produz no ser humano sentimentos de autoconfiança, prazer e satisfação, importantes para a saúde emocional; (b) nesse sentido, impedir ou dificultar o desenvolvimento dos comportamentos criativos seria uma forma de limitar a auto-realização do homem; e, (c) diante do cenário atual, repleto de incertezas, desafios e mudanças em ritmo acelerado, é necessário promover o comportamento criativo, ou seja, criar condições que aumentem a probabilidade de sua ocorrência, como forma de tentar lidar com a imprevisibilidade.

Skinner (1968/1972), ao se ocupar dessas reflexões, identificou nas práticas educativas graves erros, uma vez que a escola parece não preparar o aluno para relacionar-se produtivamente com situações novas, o que traz consequências potencialmente deletérias para a sobrevivência da cultura no que diz respeito ao enfretamento de desafios inesperados (imprevisíveis). Um desses erros consiste em considerar que o comportamento criativo não pode ser aprendido.

Segundo Alencar $(1998,2007)$, para a grande maioria dos professores e alunos, a criatividade é vista como um talento inato, presente apenas em algumas pessoas. Esta autora descreve alguns dos principais mitos sobre o comportamento criativo que estão presentes nos discursos de professores e alunos, como por exemplo, "Criatividade é algo apresentado apenas por gênios e artistas"; "Criatividade é uma característica inata e que, portanto, não pode ser ensinada ou aprendida"; "Criatividade depende apenas de fatores do próprio indivíduo"; "Criatividade é uma questão de tudo ou nada, sendo alguns indivíduos considerados criativos e outros não"; "Criatividade só ocorre em atividades artísticas"; "Criatividade depende apenas da inspiração do indivíduo".

Uma implicação dessas diferentes crenças e afirmações sobre criatividade é que elas desestimulam a criação de estratégias de ensino capazes 
de desenvolver comportamentos criativos porque se criatividade é um talento inato, há pouco a ser feito por aquelas pessoas que, supostamente, nasceram sem esse dom. Assim, a possibilidade de ampliar a habilidade de o homem lidar com novos ambientes fica limitada e, sobretudo, desacreditada.

De acordo com Skinner (1968/1972):

Nada se ganha ao afirmar que o aluno se comporta de forma criativa porque possui algo chamado criatividade. Talvez se possa medir a característica, comparar pessoas em relação a ela, testar a presença de características associadas; mas não se pode alterar a própria criatividade. Os que adotam esta abordagem ficam condenados a selecionar em vez de ensinar - por ex, procura de talento, com o fim de dar uma oportunidade aos estudantes criativos de desenvolverem suas habilidades especiais. Se tivermos que planejar meios eficazes de incrementar os comportamentos que mostram criatividade, é preciso recorrer a manipulação de variáveis (Skinner, 1968/1972, p. 159-160).

Portanto, considerar a criatividade como inata, como produto de alguma entidade que se encontra dentro do homem ou como causa ou determinante do comportamento criativo é uma condição paralisante, que apenas reafirma que as variáveis das quais o comportamento criativo é função são desconhecidas. Com efeito:

$\mathrm{O}$ professor que acredita que o estudante cria uma obra de arte por meio do exercício de alguma faculdade interior e caprichosa não investigará as condições sob as quais o estudante de fato faz um trabalho criativo. Será também menos capaz de explicar esse trabalho quando ocorrer e não tenderá a induzir os estudantes a se comportarem criativamente. (Skinner, 1968/1972, p. 160-161)

Além disso, essas teses internalistas sobre o comportamento geram sentimentos de incapacidade ou fracasso nos alunos que são classificados como pouco criativos.

Ao contrário do que essas teses sugerem, a Análise do Comportamento defende a possibilidade de identificar e estudar variáveis das quais o comportamento criativo é função, o que per- mite sugerir estratégias para a promoção desses comportamentos (Epstein, 1996). Por exemplo, Barbosa (2003) aponta quatro estratégias sugeridas por Skinner para ajudar os professores a desenvolverem em seus alunos comportamentos relacionados ao que se denomina por flexibilidade de pensamento e originalidade:

. . . (1) descrever ao aluno a forma como alguém pensou ou agiu até chegar a uma descoberta; (2) fornecer conhecimentos complementares para que o aluno possa utilizá-los na análise de novos problemas; (3) promover o comportamento exploratório individual do aluno, deixando-o em contato com as contingências referentes a um problema específico; (4) solicitar que o aluno estabeleça uma proposição ou descreva um fato de diferentes formas (Barbosa, 2003, p. 191).

Essas sugestões evidenciam a possibilidade de se desenvolver comportamentos criativos, o que, de acordo com a visão skinneriana, constitui um importante objetivo da educação porque está vinculado à preparação dos alunos para agir em novas situações no futuro.

Do exposto, pretendeu-se ter esclarecido que analistas do comportamento entendem o comportamento criativo como produto de aprendizagem por meio de contingências de reforçamento, e que o investigam com base em dois modelos, variabilidade e conexão de repertórios, que a definição comportamental de criatividade é relativa a aspectos referenciais sócio-histórico-culturais (de modo que a originalidade é apenas um dos requisitos para que se defina o efeito de um comportamento como criativo), aproximando-se, portanto, do que Alencar e Fleith (2003) denominam de "novas concepções" sobre o conceito de criatividade. Portanto, defende-se aqui, uma possibilidade de diálogo entre analistas do comportamento e outras contribuições em Psicologia da Criatividade.

Considerando o que foi discutido neste trabalho, a citação abaixo parece ser útil para sintetizar o que foi examinado:

Em uma palavra, o indivíduo é uma pessoa original, seu comportamento caracteriza-se pela excepcionalidade oriunda de uma his- 
tória idiossincrática. Sendo assim, formar indivíduos é formar pessoas criativas, é educar para a criatividade. Grosso modo, uma educação para a criatividade deve reconhecer a importância da diversidade e desenfatizar a similaridade e a reprodução. Isso significa programar condições de aprendizagem que aumentem a probabilidade da ocorrência de comportamentos originais, estimulando os acidentes e os "erros" e os "desvios" e as novidades e as inovações e as idiossincrasias com origem no comportamento do indivíduo (Abib, 2001, p. 116). Sugere-se que pesquisas futuras aprofundem o exame do comportamento criativo sob a perspectiva comportamental, apresentando dados de pesquisa empírica que demonstrem a validade das análises comportamentais ao campo da Psicologia da Criatividade. São importantes também trabalhos nessa área que confrontem e aproximem diferentes contribuições, buscando maior integração das pesquisas.

\section{Referências}

Abib, J. A. D. (1994). O contextualismo do comportamento verbal: A teoria skinneriana do significado e sua crítica ao conceito de referência. $P s i$ cologia: Teoria e Pesquisa, 10, 473-487.

Abib, J. A. D. (2001). Teoria Moral de Skinner e Desenvolvimento Humano. Psicologia: Reflexão e Crítica, 14, 107-117.

Alencar, E. M. L. S. (1998, 19 abr.). Desfazendo os mitos da criatividade. Gazeta Mercantil, p. 2.

Alencar, E. M. L. S. (2007). Criatividade no contexto educacional: Três décadas de pesquisa. Psicologia: Teoria e Pesquisa, 23, 45-49.

Alencar, E. M. L. S. de, \& Fleith, D. de S. (2003). Contribuições teóricas recentes ao estudo da criatividade. Psicologia: Teoria e Pesquisa, 19(1), 1-8.

Barba, L. S. (1997). Variabilidade comportamental aprendida (Dissertação de mestrado, Programa de Pós-Graduação em Psicologia Experimental, Universidade de São Paulo, SP, Brasil).

Barbosa, J. I. C. (2003). A criatividade sob enfoque da análise do comportamento. Revista Brasileira de Terapia Comportamental e Cognitiva, 5(2), 185-193.
Bridgman, P. (1928). The logic of modern Physics. New York: The MacMillan Company.

Carrara, K. (2005). Behaviorismo Radical: Crítica e metacrítica (2. ed.). São Paulo, SP: Editora da Universidade Estadual Paulista.

Carvalho-Neto, M. B. de (2002). Análise do Comportamento: Behaviorismo Radical, Análise Experimental do Comportamento e Análise Aplicada do Comportamento. Interação, 6(1), 13-18.

Cerutti, S. M., Ferrari, E. A. de M., Toyoda, M. S., \& Faleiros, L. (2001). Plasticidade neural: Relações com o comportamento e abordagens experimentais. Psicologia: Teoria e Pesquisa, 17(2), 187-194.

Chiesa, M. (2006). Behaviorismo Radical: A Filosofia e a Ciência. Brasília, DF: Celeiro.

Cruvinel, A. C. (2002). A produção de variabilidade de resposta pelo reforçamento de mudanças na dimensão duração (Dissertação de mestrado, Programa de Estudos Pós-Graduados em Psicologia Experimental: Análise do Comportamento, Pontifícia Universidade Católica de São Paulo, SP, Brasil).

Cupertino, C. M. B., \& Sampaio, T. P. A. (2004). Existe criatividade? A visão do behaviorismo radical. Retirado de www.ciec.org.br/Artigos/ Revista_3/cupertinosampaio.pdf

Delage, P. E. G. (2006). Investigações sobre o papel da generalização funcional em uma situação de resolução súbita de problemas ("insight") em rattus norvegicus (Dissertação de mestrado, Programa de Pós-Graduação em Teoria e Pesquisa sobre o Comportamento, Universidade Federal do Pará, Belém, PA, Brasil).

Delage, P. E. G., \& Carvalho-Neto, M. B. de. (2006). Comportamento criativo e análise do comportamento I: Insight. In H. J. Guilhardi \& N. C. de Aguirre (Orgs.), Sobre comportamento e cognição: Vol. 18. Expondo a variabilidade (pp. 345351). Santo André, SP: Esetec.

Donahoe, J. W., \& Palmer, D. C. (1994). Problem solving. In J. W. Donahoe \& D. C. Palmer, Learning and complex behavior (pp. 270-295). Boston, MA: Allyn and Bacon.

Duarte, V. R. (2004). A produção de variabilidade da dimensão duração da resposta de focinhar: Uma replicação de Cruvinel (2002) (Dissertação de mestrado, Programa de Estudos Pós-Graduados em Psicologia Experimental: Análise do Comportamento, Pontifícia Universidade Católica de São Paulo, SP, Brasil). 
Epstein, R. (1996, June-July). Libere sua Criatividade (Condensado de Psychology Today). New York: Sussex.

Epstein. R. (2008). Measuring and training creativity competencies: Validation of a new test. Creativity Research Journal, 20(1), 7-12.

Godoi, P. J. (2009). A produção de variabilidade comportamental e sua extensão para outras tarefas em crianças com desenvolvimento atípico (Dissertação de mestrado, Programa de Estudos Pós-Graduados em Psicologia Experimental: Análise do Comportamento, Pontifícia Universidade Católica de São Paulo, SP, Brasil).

Hunziker, M. H. L. (2006). Comportamento criativo e análise do comportamento I: variabilidade comportamental. In H. J. Guilhardi \& N. C. de Aguirre (Orgs.), Sobre comportamento e cognição: Vol. 18. Expondo a variabilidade (cap. 13, pp. 156-165). Santo André, SP: Esetec.

Hunziker, M. H. L., Camaroni, F. C., Silva, A. P., \& Barba, L. S. (1998). Efeitos da história de reforçamento sobre a variabilidade comportamental. Psicologia: Teoria e Pesquisa, 14(2), 149-159.

Hunziker, M. H. L., \& Moreno, R. (2000). Análise da noção de variabilidade comportamental. Psicologia: Teoria e Pesquisa, 16(2), 135-143.

Machado, A. (1993). Learning variable and stereotypical sequences of responses: Some data and a new model. Behavioral Processes, 30, 103-130.

Machado, A. (1997). Increasing the variability of response sequencesin pigeons by adjusting the frequency of switching between two Keys. Journal of Experimental Analysis of Behavior, 68, 1-25.

Medeiros, M. A. (2002). A variabilidade de seqüência de pressões à barra em diferentes condições de reforçamento (Dissertação de mestrado, Programa de Estudos Pós-Graduados em Psicologia Experimental: Análise do Comportamento, Pontifícia Universidade Católica de São Paulo, SP, Brasil).

Micheletto, N. (1997). Bases filosóficas do Behaviorismo Radical. In R. A. Banaco (Org.), Sobre comportamento e cognição: Vol. 1. Aspectos teóricos, metodológicos e de formação em Análise do Comportamento e Terapia Cognitivista (cap. 5, pp. 29-44). Santo André, SP: ARBytes.

Murari, S. C. (2004). A produção de variabilidade da dimensão duração da resposta de pressão à barra: Uma replicação de Cruvinel (2002) (Dis- sertação de mestrado, Programa de Estudos PósGraduados em Psicologia Experimental: Análise do Comportamento, Pontifícia Universidade $\mathrm{Ca}$ tólica de São Paulo, SP, Brasil).

Nico, Y. C. (2001). O que é autocontrole, tomada de decisão e solução de problemas na perspectiva de B. F. Skinner. In H. J. Guilhardi, M. B. B. P. Madi, P. P. Queiroz, \& M. C. Scoz (Orgs.), Sobre comportamento e cognição: Vol. 7. Expondo a variabilidade (cap. 7, pp. 62-70). Santo André, SP: Esetec.

Page, S., \& Neuringer, A. (1985). Variability is an operant. Journal of Experimental Psychology: Animal Behaviour Processes, 11, 429-452.

Schneider, S. M., \& Morris, E. K. (1987). A history of the Term Radical Behaviorism: From Watson to Skinner. The Behavior Analyst, 10, 27-39.

Skinner, B. F. (1931). The concept of the reflex in the description of behavior. The Journal of General Psychology, 5, 427-458.

Skinner, B. F. (1935). The generic nature of concepts of stimulus and response. The Journal of General Psychology, 12, 40-65.

Skinner, B. F. (1938). The Behavior of Organisms: An Experimental Analysis. New York: Appleton-Century-Crofts.

Skinner, B. F. (1945). The operational analysis of psychological terms. Psychological Review, 52, 270-277.

Skinner, B. F. (1972). Tecnologia do ensino (R. Azzi, Trad.). São Paulo, SP: Herder (Trabalho original publicado em 1968)

Skinner, B. F. (1978). Comportamento verbal (11. ed., M. da P. Villalobos, Trad.). São Paulo, SP: Cultrix. (Trabalho original publicado em 1957)

Skinner, B. F. (1981). Selection by consequences. Science, 213, 501-504.

Skinner, B. F. (1991). Questões Recentes na Análise do Comportamento (A. L. Néri, Trad.). Campinas, SP: Papirus. (Trabalho original publicado em 1989)

Skinner, B. F. (1998). Ciência e Comportamento Humano (10. ed., J. C. Todorov \& R. Azzi, Trads.). São Paulo, SP: Martins Fontes. (Trabalho original publicado em 1953)

Skinner, B. F. (1999). Sobre o Behaviorismo (11. ed., M. da P. Villalobos, Trad.). São Paulo, SP: Cultrix. (Trabalho original publicado em 1974) 
Todorov, J. C. (2007). A psicologia como o estudo de interações. Psicologia: Teoria e Pesquisa, 23, 57-61.

Tourinho, E. Z. (1987). Sobre o surgimento do behaviorismo radical de Skinner. Psicologia, 13, $1-11$.

Tourinho, E. Z. (1999). Estudos conceituais na análise do comportamento. Temas em Psicologia, $7(3), 213-222$.
Zanella, A. V., \& Titon, A. P. (2005). Análise da produção científica sobre criatividade em programas brasileiros de pós-graduação em psicologia (1994-2001). Psicologia em Estudo, 10(2), 305316.

Recebido: $25 / 02 / 2013$

Aceite final: 25/02/2013 